$$
\text { CONF- } 960988--2
$$

\title{
United States Department of Energy Thermally Activated Heat Pump Program
}

\author{
R. J. Fiskum* \\ P. W. Adcock \\ R. C. DeVault
}

*Department of Energy, Washington DC

to be presented at

1996 International Absorption Heat Pump Conference

Montreal, Canada

September 17-20, 1996

\author{
Prepared for the \\ OAK RIDGE NATIONAL LABORATORY \\ Oak Ridge, Tennessee 37831 \\ managed by \\ LOCKHEED MARTIN ENERGY RESEARCH CORP. \\ for the \\ U.S. DEPARTMENT OF ENERGY \\ under Contract No. DE-AC05-960R22464
}

\begin{abstract}
"The submitted manuscript has been authored by a contractor of the U.S. Government under contract No. DE-AC05-96OR22464. Accordingly, the U.S. Government retains a nonexclusive, royalty-free license to publish or reproduce the published form of this contribution, or allow others to do so, for U.S. Government purposes."
\end{abstract}




\section{DISCLAIMER}

This report was prepared as an account of work sponsored by an agency of the United States Government. Neither the United States Government nor any agency thereof, nor any of their employees, makes any warranty, express or implied, or assumes any legal liability or responsibility for the accuracy, completeness, or usefulness of any information, apparatus, product, or process disclosed, or represents that its use would not infringe privately owned rights. Reference herein to any specific commercial product, process, or service by trade name, trademark, manufacturer, or otherwise does not necessarily constitute or imply its endorsement, recommendation, or favoring by the United States Government or any agency thereof. The views and opinions of authors expressed herein do not necessarily state or reflect those of the United States Government or any agency thereof. 


\section{DISCLAIMER}

Portions of this document may be illegible in electronic image products. Images are produced from the best available original document. 


\title{
UNITED STATES DEPARTMENT OF ENERGY THERMALLY ACTIVATED HEAT PUMP PROGRAM
}

\author{
R.J. Fiskum', P. Welesko Adcock ${ }^{2}$, R.C. DeVault ${ }^{2}$
}

'United States Department of Energy, 1000 Independence Ave., Washington, DC, USA, Tel: 202-586-9154

Fax: 202-586-1628

${ }^{2}$ Oak Ridge National Laboratory, Oak Ridge, Tennessee, USA, Tel: 423-574-2694 Fax: 423-574-9329

\begin{abstract}
The United States Department of Energy (DOE) is working with partners from the gas heating and cooling industry to improve energy efficiency using advance absorption technologies, to eliminate chlorofluorocarbons (CFCs) and hyrochlorofluorocarbons (HCFCs), to reduce global warming through more efficient combustion of natural gas, and to impact electric peak demand of air conditioning. To assist industry in developing these gas heating and cooling absorption technologies, the U. S. DOE sponsors the Thermally Activated Heat Pump Program. It is divided into five key activities, addressing residential gas absorption heat pumps, large commercial chillers, advanced absorption fluids, computer-aided design, and advanced "Hi-Cool" heat pumps.
\end{abstract}

\section{LIST OF SYMBOLS AND ABBREVIATIONS}

\author{
ABSIM - ABsorption SIMulation \\ CFC - Chlorofluorocarbon \\ COP - Coefficient of Performance \\ DCC - Double-Condenser Coupling \\ DOE - Department of Energy \\ HCFC - Hydrochlorofluorocarbon \\ $\mathrm{H}_{2} \mathrm{O}$ - Water \\ $\mathrm{LiBr}$ - Lithium Bromide \\ $\mathrm{NH}_{3}$ - Ammonia \\ ORNL - Oak Ridge National Laboratory
}

\section{INTRODUCTION}

Gas-fired heating and cooling systems offer many benefits to consumers, utilities, and the regional and global environment. For end users, they offer energy efficiency and attractive economic payback. For utilities, they offer alternatives to reduce peak electric demand and improve fuel use through integrated resource planning and demand-side management, with benefits for both gas and electric utilities. For the nation, advanced gas heating and cooling products create new jobs in the United States and improve our competitiveness in international markets. Additionally, this environmentally benign technology eliminates the use of ozone-depleting chlorofluorocarbon (CFC) and hydrochlorofluorocarbon (HCFC) refrigerants.

The Office of Building Technologies of the Department of Energy (DOE) supports private-sector efforts to develop gas heating and cooling technologies through its Thermally Activated Heat Pump Program. Oak Ridge National Laboratory (ORNL) manages this program for the Department of Energy.

\section{RESIDENTIAL GAS ABSORPTION HEAT PUMP}

DOE's Generator-Absorber heat eXchanger (GAX) concept, originally described by Altenkirch in 1913, was not put into practice until the early 1980s. Altenkirch showed a generator and absorber operating with overlapping temperatures. An energy-recovery heat-exchange loop between the generator and absorber raises the thermal efficiency by recovering the heat energy released through an exothermic reaction when the ammonia refrigerant mixes with water in the absorber. Although the GAX is a simple thermodynamic concept, it is difficult to achieve in compact hardware. Thermal gradients are "upsidedown" (in terms of gravity) and a mismatch exists in the heat quantities between the absorber and generator.

In the GAX process, a mixture of water and ammonia is pressurized by a pump and heated in the generator by a natural gas flame. The more volatile component, the ammonia, boils out of the mixture and travels to a condenser as a pure refrigerant, where it releases heat and condenses back into a liquid. The cooled ammonia liquid then travels to an evaporator where it picks up heat from the outside environment, providing cooled water for space cooling. Converted back to vapor, the ammonia is then recombined with water. 
The heat produced by the condensing process can be used for space heating. Aside from the natural gas burned in the process, the only other energy requirement is for electricity to drive the circulation pumps and fans.

The basic GAX technology for residential and small commercial applications has been developed principally by Phillips Engineering with DOE sponsorship, under an ORNL-directed subcontract. Phillips Engineering was the first to demonstrate GAX hardware by building and successfully testing a laboratory breadboard prototype in 1984-1985 [1]. This breadboard demonstrated significant efficiency improvement, having a heating coefficient of performance (COP) of 1.6 to 1.8 (including flue losses from the gas burner, but excluding electric parasitics) and a cooling $\mathrm{COP}$ of 0.7 to 0.9 . These COPs are based on the heat content of the natural gas. An additional advantage is that in the heating mode, the GAX system offers much lower nitrogen oxide emissions compared with electricity produced from coal. Figure 1 compares the heating COP of the GAX absorption heat pump to the efficiency of the gas furnace.

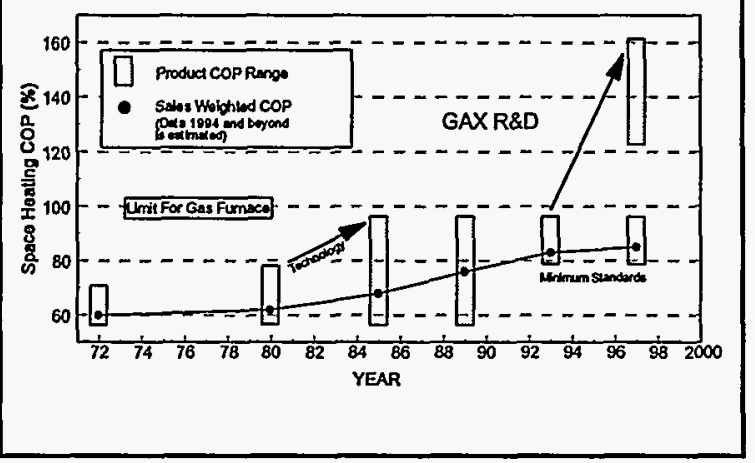

Figure 1. Comparison of heating efficiency of gas furnace and GAX heat pump.

In 1990, ORNL subcontracted with Battelle Memorial Institute to investigate alternative absorber designs and to build an absorber test loop to assist with component dynamic testing [2].

The DOE program continued with development of proof-of-principle packaged prototypes. In 1992, Phillips invited potential manufacturers to consider licensing the technology. In 1993, two GAX absorption sealed systems and one complete GAX heat pump developed by Phillips under the DOE program were delivered to Carrier Corporation for independent testing and evaluation. The proof-of-principle was confirmed by Carrier. After conducting independent cost and market studies to assess commercial feasibility and business opportunities, Carrier concluded that the GAX technology could become a significant mainstream product in the United States and worldwide.

The new design offers improved heating and cooling efficiency because using natural gas avoids energy conversion and distribution losses (approximately $65-70 \%$ ) incurred when electricity is used. This factor, plus predicted lower maintenance costs due to fewer moving parts than a gas furnace and vacuum compression air conditioner, results in lower costs for the consumer. These factors are in addition to the previously mentioned environmental benefits.

Final licensing by Carrier was completed in October 1993. Phillips Engineering's technology is the "starting point" for the GAX heat pump, but substantial work remains to improve its manufacturability. The American Gas Cooling Center has developed a cost-shared gas industry consortium to facilitate development and adoption of the GAX technology while DOE/ORNL is providing a cost-share, technical support and development guidance, leading the effort to achieve even higher efficiencies.

\section{LARGE COMMERCIAL CHILLER}

The second key activity in the DOE Thermally Activated Heat Pump Program is a large commercial triple-effect chiller program, using the $\mathrm{LiBr} / \mathrm{H}_{2} \mathrm{O}$ fluid pair and operating at higher temperatures than current technology. The goal of DOE's program is to improve cooling efficiency by 30 to 50 percent, compared with double-effect absorption chillers currently on the market.

Various absorption chillers using $\mathrm{NH}_{3} / \mathrm{H}_{2} \mathrm{O}$ and $\mathrm{LiBr} / \mathrm{H}_{2} \mathrm{O}$ absorption pairs for commercial and residential use were built and patented during the 1950 's, 1960's, and 1970's. The first double-effect machine was built in 1956-1959 by J. S. Swearingen and E.P. Whitlow in a program sponsored by the American Gas Association. This double-effect cycle has been extensively improved upon and is sold throughout the world by numerous United States and Japanese corporations. While building the first double-effect chiller, Swearingen and Whitlow considered building a triple-effect cycle by "doing it 
again", however they decided against it, rationalizing that the generator temperature needed for triple-effect would be "too high" for practical applications. Figure 2 shows relative energy usage for single, double, and triple-effect large commercial absorption chillers.

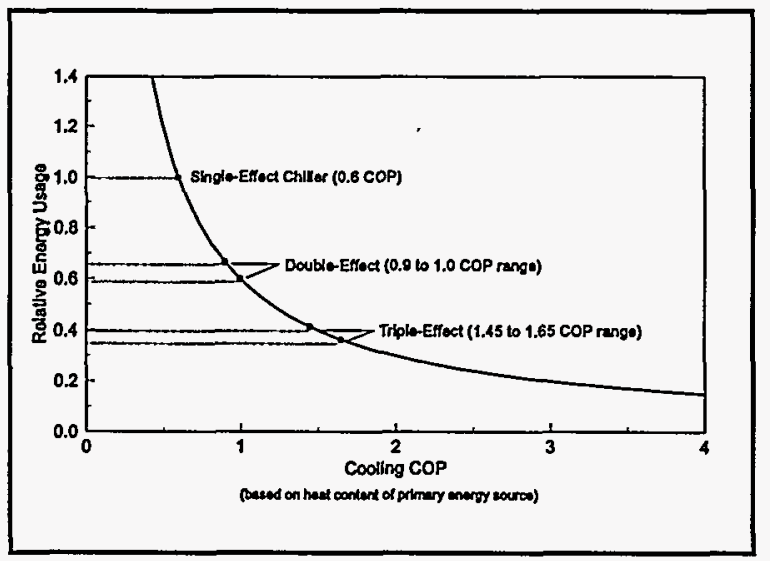

Figure 2. Relative Energy Usage for Large Commercial Chillers.

Currently, there are no triple-effect absorption chillers sold commercially. Previous work has shown that there are theoretically a large number of cycles that fall into the category of "triple-efficiency" $[3,4,5,6,7,8,9]$. The basic three-condenser-threedesorber $\mathrm{LiBr} / \mathrm{H}_{2} \mathrm{O}$ triple-effect cycle was patented in 1985 by Oouchi, et.al. [5]. A "dual-loop" triple-effect cycle was patented in 1989 by ORNL under the DOE Thermally Activated Heat Pump Program [7]. A pressure versus temperature representation for the "dual-loop" triple-effect cycle is shown in Figure 3.

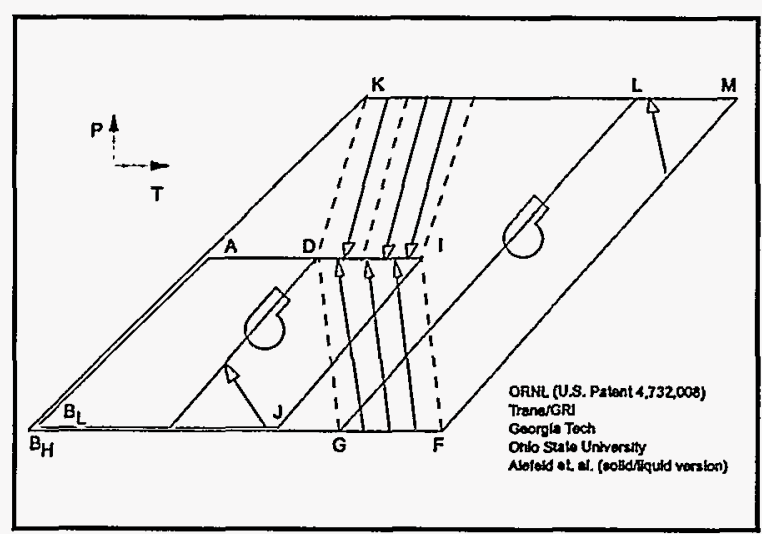

Figure 3. Pressure vs. Temperature Diagram for the dual-loop triple-effect cycle.

Trane Company licensed the triple-effect technology from ORNL in 1989. With support from the Gas
Research Institute, Trane has built an operational triple-effect prototype, of greater than 100-ton capacity, which is undergoing optimization and characterization testing. Trane's product goal is a 50 percent improvement in COP with no more than a 25 percent cost premium over the current double-effect chillers on the market.

Since the Trane/GRI dual-loop, triple-effect program was underway, DOE and ORNL conducted additional scoping studies to identify promising alternative tripleeffect technologies. Alternate technologies were extensively reviewed, including 3, 4, 5, 6 and 7 effects. One particular triple-effect cycle, using a double-condenser coupling (DCC) concept, emerged as the best alternative and was patented by ORNL in 1993 [8]. A pressure versus temperature representation for the DCC concept is shown in Figure 4.

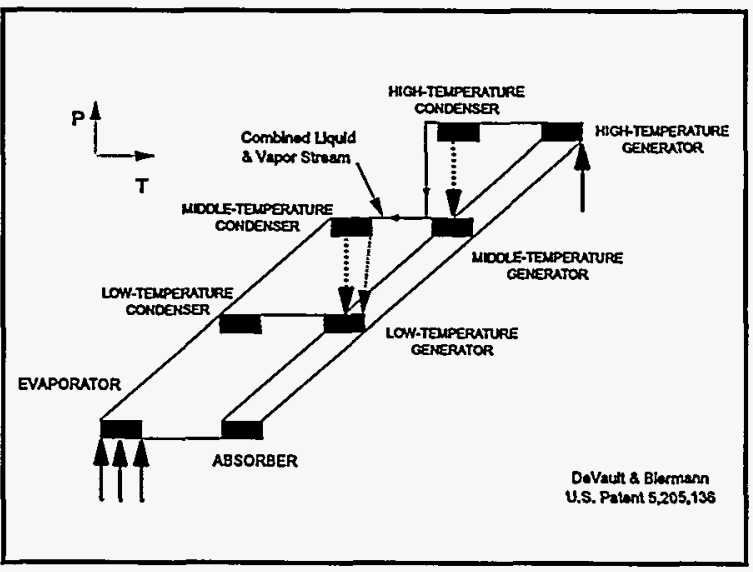

Figure 4. Pressure vs. Temperature Diagram for the DCC triple-effect cycle.

The primary technical challenges in building a tripleeffect chiller include controlling material corrosion in the highest temperature stages (upper stage generator and hot side of the upper stage solution heat exchanger), and preventing thermal decomposition of the heat transfer additive caused by increased temperatures. The challenge is to produce a machine that is $30-50 \%$ more efficient than a double-effect chiller and is economically viable. Predicted initial manufacturing cost of the triple-effect machine is somewhat higher than that of double-effect machines. The higher manufacturing costs result from more expensive materials of construction needed to reduce corrosion rates, larger heat exchanger surface areas, higher operating pressures, and more complicated control systems. 
The DOE large commercial chiller program involves research, development and evaluation of multiple triple-effect designs. As part of the program, ORNL contracted with Battelle Memorial Institute to study corrosion of materials in $\mathrm{LiBr} / \mathrm{H}_{2} \mathrm{O}$ high temperature applications [9]. In a cost-shared subcontract with York International, ORNL has reviewed several cycle possibilities for $\mathrm{LiBr} / \mathrm{H}_{2} \mathrm{O}$ triple-effect absorption chillers. The DCC cycle is currently the base cycle being investigated by York International under this cost-shared project. The objective of this project is to build fully functional hardware to demonstrate a practical triple-effect chiller for commercial air conditioning applications. The design goal for the prototype is to achieve 400 tons of cooling capacity. The final goal is a U.S. manufactured triple-effect absorption chiller.

The task outline for the Large Commercial Chiller project is shown in Figure 5. DOE/ORNL is providing development support and technical guidance to York International in this cost-shared program to develop a triple-effect absorption chiller prototype. The Gas Research Institute is also providing a cost-share in this program. DOE is working with manufacturers and gas utilities to disseminate information related to commercial gas cooling technologies.

\section{HI-COOL HEAT PUMP}

ORNL conducted a competitive procurement and multiple subcontractors were selected to perform work under Phase I of the Hi-Cool heat pump program. Work has started at Battelle/ARCTEK, Energy Concepts, Phillips Engineering, Rocky Research and R.A. Technology. Additional subcontracts are under negotiation.

The fluids derived from the advanced fluids program and computer modeling technologies are being integrated into the design of the Hi-Cool heat pump, which has the goal of a 30 percent improvement in cooling performance over that of the current best available technology. The benefits of the Hi-Cool unitary heat pump include year-round energy-use reduction and expansion of the market for gas-fired heat pumps.

Four work phases are in progress:

- Analytical evaluation and selection of best cycle(s)

- Critical component development

- Laboratory proof-of-principle experiments

- Development and commercialization

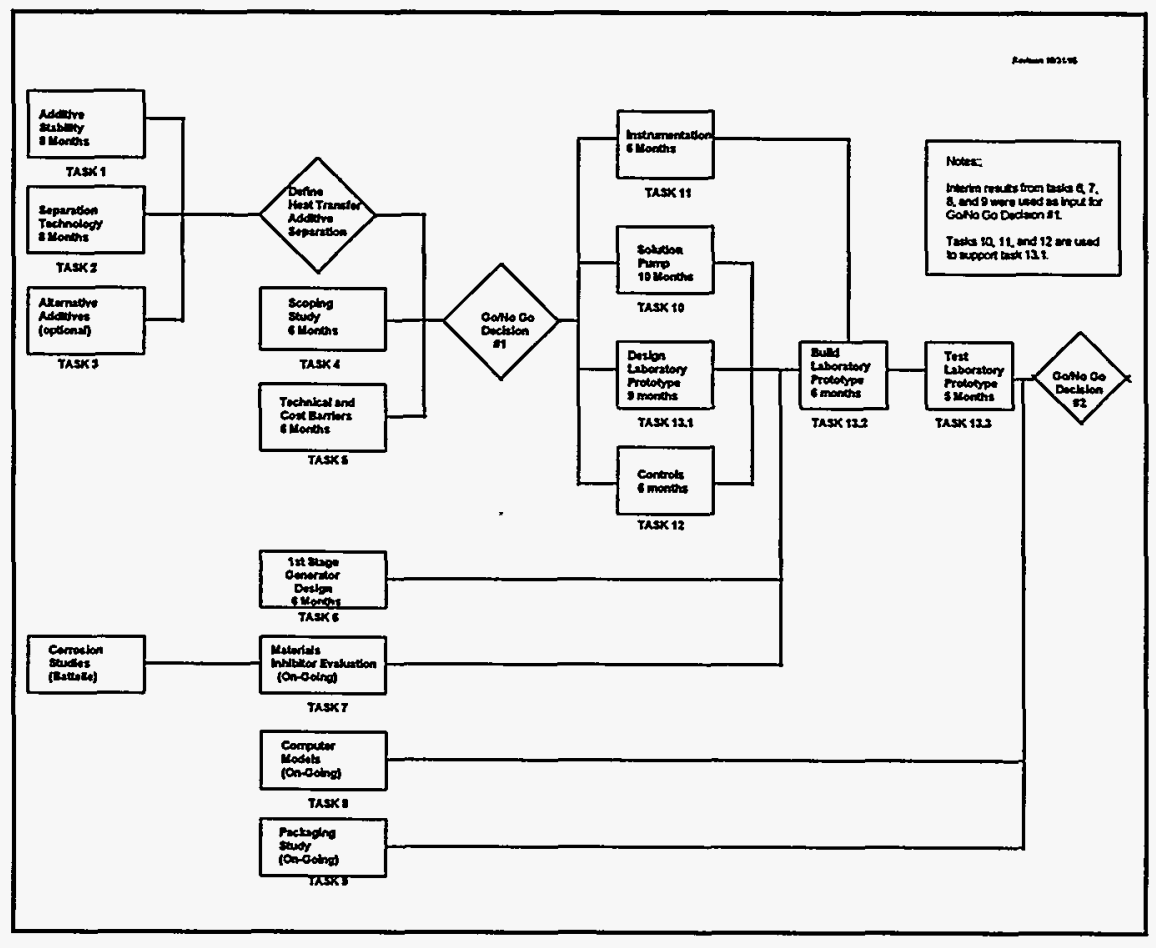

Figure 5. Task Outline for the Large Commercial Chiller Program 
Phase II will include construction and proof-ofprinciple testing for a laboratory prototype. Each Phase II bidder is required to have a manufacturing partner to assist with the prototype development. The Phase II program is expected to start this year.

\section{ADVANCED ABSORPTION FLUIDS}

ORNL is developing advanced absorption fluids for the Hi-Cool heat pump. Ternary, and quaternary ammonia mixtures have been studied at Technical University of Munich, Trane, Carrier, Phillips, and ORNL. All of these analyses demonstrated that salt mixtures could increase temperature overlap, thereby improving cooling performance in the basic ammonia GAX cycle. However, experiments at Phillips, Carrier, and Trane with different mixtures produced excessively high corrosion.

Recent work at ORNL (see task outline Figure 6) has identified a new promising ammonia quaternary mixture, Q2. Electrochemical corrosion tests and stress corrosion cracking tests on metal coupons indicate the ORNL Q2 mixture is no more corrosive than $\mathrm{NH}_{3} / \mathrm{H}_{2} \mathrm{O}$ at $\mathrm{GAX}$ temperatures. Heat and masstransfer testing has been completed in an absorber test loop at ORNL. Property data (i.e., PTX, enthalpy), needed for detailed performance calculations, has been determined by the University of Maryland, Texas A\&M, and Wiltec. Modeled performance calculations conducted by ORNL indicate that the Q2 mixture provides the best performance enhancement over the binary $\mathrm{NH}_{3} / \mathrm{H}_{2} \mathrm{O}$ mixture at temperatures in excess of $200^{\circ} \mathrm{C}$, which is the temperature range where corrosion is the most active and must be considered. Subsequent electrochemical corrosion studies of Q2 mixtures with several different steel alloys using corrosion inhibitors at higher temperatures showed promising results. Future work includes experimental performance tests of the Q2 fluid in a GAX system.

\section{COMPUTER-AIDED DESIGN}

The computer-aided design effort has focused primarily on the development of ABsorption SIMulation (ABSIM), an absorption-cycle model that is modular in structure. ABSIM was developed by Gershon Grossman at ORNL and Technion University, Israel $[11,12]$. ABSIM provides a tool to investigate various cycle configurations with different working fluids, calculate operating parameters, predict performance and make comparisons on a uniform basis. The structure of the ABSIM program is shown in Figure 7. The code is based on unit subroutines containing the governing equations for the system's

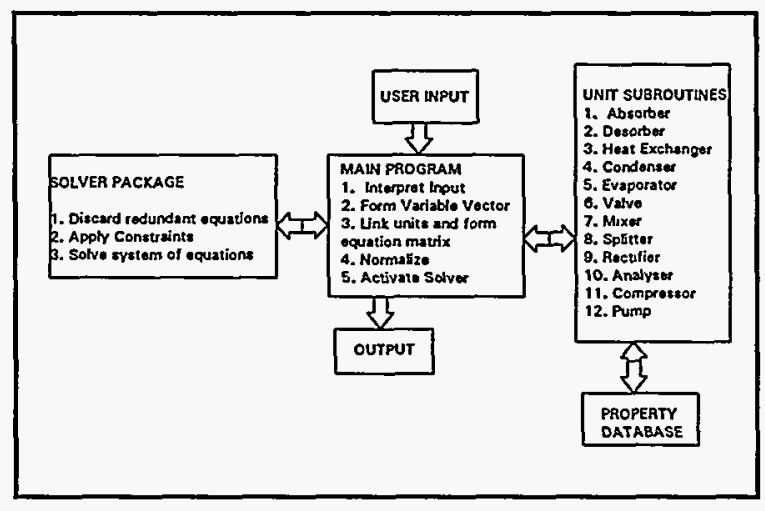

Figure 7. Structure of ABSIM Code.

components. The components are linked together by a main program according to the user's specifications to form the complete system. When all equations have

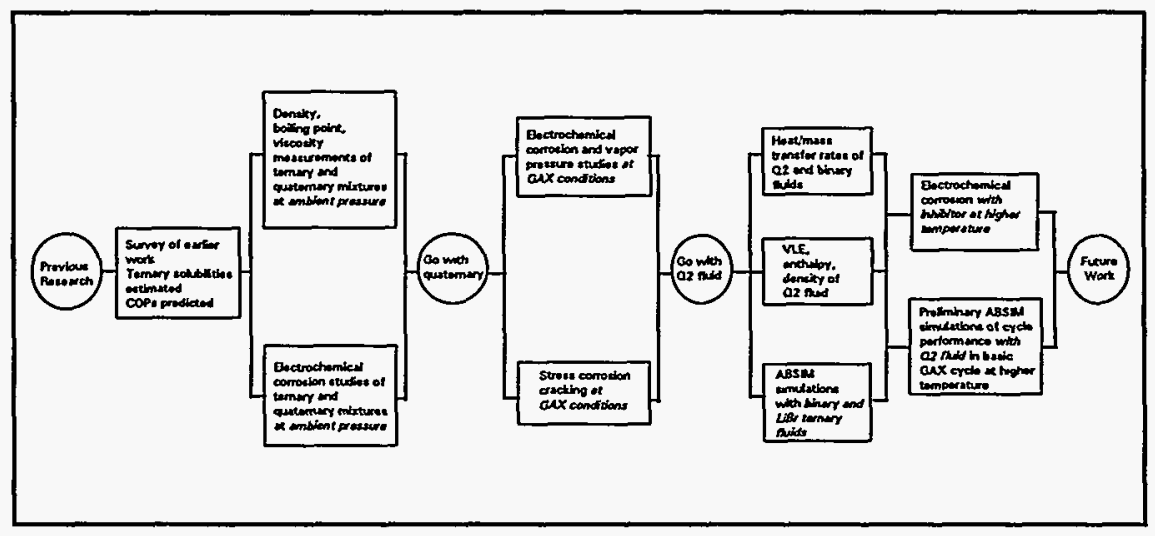

Figure 6. Task Outline for the Fluids Program 
been established, a mathematical solver routine is employed to solve the equations simultaneously. Property subroutines are contained in a separate data base to provide thermophysical properties of the working fluids. A graphical user interface enables the user to draw the cycle diagram on a computer screen, enter the input data interactively, run the program and view the results either as a table or superimposed on the cycle diagram.

In addition to ABSIM, ORNL is developing computer models to bridge the gap between system modeling and component modeling. ORNL is developing, from first principles, a model of the absorber for the GAX heat pump using design information from Phillips Engineering. The goal is to have a working model based on each component in the GAX heat pump.

\section{BOOKS}

DOE supports training and education of students, scientists, and engineers. Two books have been published under DOE co-sponsorship. Absorption Chillers and Heat Pumps [13] was written for undergraduate students to introduce them to fluid mixtures, absorption cycles, and absorption equipment. Senior design students may use the computer disk to solve the example problems from the book or more difficult classroom problems. Heat Conversion Systems [14] was tailored for graduate students in the field of energy conversion, refrigeration, heating and air conditioning, applied physics, and mechanical and chemical engineering. It discusses more advanced systems such as multistage, multi-effect cycles.

\section{ACKNOWLEDGEMENTS}

The authors would like to thank the Office of Building Technologies, U.S. Department of Energy, in Washington, D.C. for supporting this work.

\section{REFERENCES}

[1] B. A. Phillips, Development of a High-Efficiency, Gas-Fired, Absorption Heat Pump for Residential and Small-Commercial Applications, ORNL/Sub/8624610/1, January, 1991.

[2] W. T. Hanna, Absorber Development for a GAX Heat Pump, Battelle Memorial Institute, March 10,
1995.

[3] Personal communication with Gene Whitlow, October 4, 1994.

[4] G. Alefeld, Multi-Stage Apparatus Having Working-Fluid and Absorption Cycles, and Method of Operation Thereof, U.S. Patent 4,531,374, July 30, 1985.

[5] T. Oouchi, S. Usui, T. Fukuda, and A. Nishiguchi, Multi-Stage Absorption Refrigeration System, U. S. Patent, 4,520,634, June 4, 1985.

[6] N. Miyoshi, S. Sugimoto, and M. Aizawa, MultiEffect Absorption Refrigerating Machine, U.S. Patent 4,551,991, November 12, 1985.

[7] R. C. DeVault, Triple-Effect Absorption Chiller Utilizing Two Refrigerant Circuits, U.S. Patent 4,732,008, March 22, 1988.

[8] R. C. DeVault and W. J. Biermann, TripleAbsorption Refrigeration System With DoubleCondenser Coupling, U.S. Patent 5,205,136, April 27, 1993.

[9] U. Rockenfeller and P. Sarkisian, Triple-Effect Absorption Cycle Apparatus, U.S. Patent 5,335,515, August 9, 1994.

[10] W. T. Hanna, Development and Proof Testing of Basic Technology Needed for High Temperature Operation of $\mathrm{LiBr} / \mathrm{H}_{2} \mathrm{O}$ for Absorption Chiller Cycles, Battelle Memorial Institute, March 31, 1995

[11] G. Grossman and M. Wilk, Enhanced Absorption Cycle Computer Model, ORNL/Sub/91-SH641/1, 1993.

[12] G. Grossman, ABSIM-Modular Simulation of Absorption Systems, User's Guide and Reference, Version 1.01, Oak Ridge National Laboratory, February, 1995.

[13] K. E. Herold, S.F. Kline, and R. Radermacher, Absorption Chillers and Heat Pumps, CRC Press, Boca Raton, 1996.

[14] G. Alefeld and R. Radermacher, Heat Conversion Systems, CRC Press, Boca Raton, 1994. 